\title{
An analysis of discourse style in English translation of Hedayat's Fiction, Boof-e-Koor, under Hallidayan model
}

\section{Khatereh Vatandoost*, Mehrangiz Anvarhagigi}

\author{
Department of Foreign Languages, University College of Nabi Akram, Tabriz, Iran \\ *Corresponding author
}

\begin{abstract}
The present research aims at analyzing discourse style of the Persian fiction, Boof-e-Koor, by Hedayat and its English translation, The Blind Owl, by Bashiri under model of discourse analysis by Michael Halliday's functional model. Research method used here is analytic, interpretive, qualitative one. To this end, whole corpus was selected as required data to be analyzed by Hallidayan functional model. According to the results from the present research, English translation of Boof-e-Koor is understood to be a formal written fiction with simple prose style.
\end{abstract}

Keywords-Discourse, Fiction, Hallidayan Model, Style, Translation.

\section{INTRODUCTION}

Translation studies have seen many shifts over the time. Cultural turn occurred in 1980s with a new approach known as "functionalism" focusing more on culture and function than the language. Among the forerunners of the functionalists are Michael Halliday, Hans J. Vermeer, Katharina Reiss, Justa Holz-Manttari, and Christiane Nord with the emphasis of the followers of this approach on the aim and the purpose of the translation (Baker and Saldanha, 2013, p. 117). In the 1990s discourse analysis came to prominence in translation studies, drawing on developments in applied linguistics. There is a link with the text analysis model of Christian Nord in the organization of the text above sentence level. However, while text analysis normally concentrates on describing the way in which texts are organized (sentence structure, cohesion, etc.), discourse analysis looks at the way language communicates meaning and social and power relation. The model of discourse analysis that has had the greatest influence is Michael Halliday's functional model (Munday, 2011, p. 137), which is studied in present research.

The English translation of Sadeq Hedayat's masterpiece, Boof-e-Koor, (translated in English as The Blind $O w l$ ) by Iraj Bashiri has appealed many readers in the U.S.A (Katouzian,
2008). Previously, many scholars have analyzed The Blind Owl using various theories and models of translation. However, a little attention has been paid to the case of discourse style under the Hallidayan model in this wellknown fiction. One of the problems, regarding the function of translation, included in the translation act is the extent to which a translator can preserve both texts as close as possible to each other in rendering from source text into target text, especially a literary text. The purpose of the present research is to analyze the discourse style established in the translated version of Boof-e-Koor, hence it can contribute to the efficiency of the research for those who are involved in learning, teaching, and investigating fiction works under the Hallidayan functional model. The examination of the previous literature suggests evidently that in spite of the abundance of the studies conducted under the Hallidayan functional model, just few of them concerned with the fiction texts, but none studied the translated texts from Persian into English. The question to be answered here is that how does the translated version of Boof-e-Koor fulfill the basic requirement of discourse style?

In the early 20th century, linguistics has witnessed a considerable number of theories and each one has its distinct orientations, trends, and subjects of study. One of the most substantial theories is Halliday's Systemic Functional 
Linguistics (often SFL) that has attracted the most attention and has been frequently employed in the literature on linguistics and applied linguistics (Almurashi, 2016, p.71). SFL, with regards to data, does not tackle the manner of language representation or process in the human brain, but would rather try to see discourses produced in the form of written or oral language and what is contained in the tests that are produced. Because of the concern of SFL with the use of language, great importance is placed on the function of language, such as what language is used for, rather than what language structure is all about and the manner by which it is composed (Matthiessen and Halliday, 1997as cited in Almurashi, 2016, p.71).

A research entitled "A Stylistic Analysis of Some of Golestan Stories Using Halliday's Systemic Functional Linguistics Framework" by Mehrabi and Zaker (2014) Systemic Functional framework of Halliday has been used to investigate stylistically some of Golestan proses in order to answer these questions: What linguistic elements have been foregrounded in each story (chosen at random) and which experiential metafunctions has been used in each one? What is the reason of its application and does the metafunctions foreground the content of the story? The hypothesis is that the contents of the stories are in a close relation to the linguistic forms used in each story. In other words, the content has been foregrounded in the form. After analyzing the data, results showed that the writer's intended content is in accordance with the communicative experiential metafunctions in terms of frequency of occurrence, but significant differences are recognizable only when the total number of verbs is bigger as the story is longer. Also, Sa'di realism is represented in the relational verbs.

Another research conducted by Wang (2010) under the title of "A Critical Discourse Analysis of Barack Obama's Speeches" states that The Critical Discourse Analysis is often applied to analyze political discourse including the public speech, in which the speaker wins favorite response from the audience. This paper, based on Critical Discourse Analysis theory and Systematic Functional Linguistics, analyzes Barack Obama's presidential speeches mainly from the point of transitivity and modality, in which we can learn the language how to serve the ideology and power. Moreover, we can have a better understanding of the political purpose of these speeches.

The present paper can make a contribution to the critics, researchers and readers of fiction works. The results from this research can contribute to a reader-ideal translation of fiction from Persian into English Also, it can contribute to the efficiency of the translation under Hallidayan discourse analysis in works of those who are involved with the learning, teaching and investigating fictions under skopos theory.

\section{METHODOLOGY}

The approach to take to one's research should be determined by the research question(s) and how best it/they might be addressed. A qualitative approach is generally associated with the interpretivist position (Saldanha \& Sharon, 2014, p. 22). Considering the present research question inquiring how does the translated version of Boof-e-Koor fulfill the basic requirement of discourse style it becomes clear that this research is a descriptive qualitative and the corpus under investigation is English version of a Persian fiction. As it has been intended to analyze the whole text of the novel, the sampling methods were not applied, that is, for the purpose of the current study and in order to yield reliable results, the whole book was gone under the investigation. Also, it is worth mentioning that the unit of analysis was selected to be sentence level. The instrument of collecting and analyzing data is discourse analysis. The theoretical framework is Hallidayan functional model.

\subsection{Literary Discourse and Translation}

\subsubsection{Literary Translation}

Translation is closely connected with stylistics because stylistics aims to explain how a text means rather than just what it means, and knowing how texts mean is essential for translation. Stylistics explains the fine detail of a text such as why certain structures are ambiguous or how a metaphor works, and is used to describe both literary and non-literary texts. Originally a development of linguistics, stylistics began to take shape as a distinct discipline in the 1960s, influenced by the close-reading methods of literary theorists such as I.A. Richards and by the structuralist linguistic and literary methods of scholars such as Roman Jakobson (Gambier and Doorslaer, 2011, p.153).

Literary translation is a type of translation that is distinguished from translation in general. A literary translation must reflect the imaginative, intellectual and intuitive writing of the author. In fact, literature is distinguished by its aesthetics. Belhaag (1977, p. 20 as cited in Salmani and Khorsand, 2014, p. 61) summarizes the characteristics of literary translation as "expressive, connotative, symbolic, focusing on both form and content, 
subjective, allowing multiple interpretation, timeless and universal, using special devices to heighten communicative effect, tendency to deviate from the language norms" (Hassan, 2011, pp. 2-3 as cited in Salmani and Khorsand, 2014, p. 61).

\subsubsection{Novel/Fiction Discourse}

The definition of the term "novel" may differ from one scholar/dictionary to another. Chandler (2007, as cited in Salmani and Khorsand, 2014, p. 61) believes that "a novel is a long prose narrative that usually describes fictional characters and events in the form of a sequential story."

According to Smiley (2005, p. 14 as cited in Salmani and Khorsand, 2014, p. 61) "a novel is a (1) lengthy, (2) written, (3) prose, (4) narrative with a (5) protagonist." She continues "everything that the novel is and does, every effect that the novel has had on, first, Western cultures, and subsequently, world culture, grows out of these five small facts that apply to every novel." Chandler (2007, as cited in Salmani and Khorsand, 2014, p. 61) discusses that "novel is today the longest genre of narrative prose, followed by the novella, novelette and the short story." Regarding the difference between a novella and a novel, he states that "there is no consensus as to the minimal required length..., the boundary between a novella and a novel may be arbitrary and difficult to determine." Smiley (2005, p. 15 as cited in Salmani and Khorsand, 2014, p. 61) states that "all additional characteristics- characters, plot, themes, setting, style, point of view, tone, historical accuracy, philosophical profundity, revolutionary or revelatory effect, pleasure, enlightenment, transcendence, and truth-grow out of the ironclad relationships among these five elements." Considering a novel as an experience, Smiley (p. 15) argues that this experience "takes place within the boundaries of writing, prose, length, narrative, and protagonist." She believes that writing has the utmost importance among the five qualities of the novel. By focusing on "the paradox of writing" as it "is permanent" and "may be forgotten", the "author and reader agree that images and ideas set down in writing may come and go because they do not have to be stored in memory" (Smiley, 2005, p. 15 as cited in Salmani and Khorsand, 2014, p. 62).

Smiley (p. 24 as cited in Salmani and Khorsand, 2014, p. 62) discusses that "the most important essential characteristic of the novel that arises out of its structure, out of the combination of narrative and length, is that it is inherently political."

\subsubsection{Hallidayan Model of Style Discourse:}

The functional paradigm views discourse as language use (Schiffrin, 1994, p. 20 as cited in Salmani and Khorsand, 2014, p. 23). This definition observes the relationship the discourse has with the context. The functionalist paradigm is based on two general assumptions: (a) language has functions that are external to the linguistic system itself. (b) External functions influence the internal organization of the linguistic system (Schiffrin, 1994 as cited in Salmani and Khorsand, 2014, p. 23). According to the functionalist view, the study of discourse is the study of any aspect of language use (Schiffrin, 1994, p. 31 as cited in Salmani and Khorsand, 2014, p. 23).

Functionalists such as Halliday (1985) tend to regard language as a social phenomenon and explain linguistic universals as deriving from the universality of the uses to which language is put in human society. Functionalists study language in relation to its social functions (Schiffrin, 1994, pp. 21-22 as cited in Salmani and Khorsand, 2014, p. 23). For some scholars such as Halliday discourse is language in use and discourse analysis involves purposes and functions of language in human life. They believe that discourse is a socially and culturally organized system through which particular functions are realized. They claim that discourse is as collection of contextualized units of language use (Salmani and Khorsand, 2014, p. 23).

Halliday and Hassan (1989, p. 23 as cited in Salmani and Khorsand, 2014, p. 25) state that register is a configuration of meanings that are typically associated with a particular situational configuration of field, mode, and tenor, therefore, a register must include the expressions, the lexicogrammatical and phonological features that typically accompany or realize these meanings. Halliday and Martin (1993/1996/2005) believe that the concept of genre refers to discourse types is a category superordinate to register and register in turn is the content-plane of language, with language being the expression-plane of register (Salmani and Khorsand, 2014, p. 25).

Thus, the genre (the conventional text type that is associated with a specific communicative function, for example a business letter) is conditioned by the sociocultural environment and itself determines other elements in the systemic framework. The first of these is register, which comprises three variable elements:

(1) Field: what is being written about, e.g. a delivery of goods; 
(2) Tenor: who is communicating and to whom, e.g. a sales representative to a customer;

(3) Mode: the form of communication, e.g. written.

Each of the variables of register is associated with a strand of meaning. These strands, which together form the discourse semantics of a text, are the three metafunctions: ideational, interpersonal and textual. The metafunctions are constructed or realized by the lexicogrammar, which is the choice of wording and syntactic structure. The links are broadly as follows (see Eggins, 2004, p.78 as cited in Munday, 2011, p. 91): The field of a text is associated with ideational meaning, which is realized through transitivity patterns (verb types, active/passive structures, participants in the process, etc.). The tenor of a text is associated with interpersonal meaning, which is realized through the patterns of modality (modal verbs and adverbs such as hopefully, should, possibly, and any evaluative lexis such as beautiful, dreadful). The mode of a text is associated with textual meaning, which is realized through the thematic and information structures (mainly the order and structuring of elements in a clause) and cohesion (the way the text hangs together lexically, including the use of pronouns, ellipsis, collocation, repetition, etc.) (Munday, 2011, p. 91).

So, considering the Hallidayan's notion, the field is identical in both texts; because the ST is a literary simple prose text, a fiction, and its translation has maintained the same field as in ST. Regarding tenor, ST addresses Persian people living Reza Shah's age; however, TT has been translated in English to non-Persian people. Mode of ST is a written literary novella and the same is true about TT.

\subsubsection{The Hallidayan Model of Language and Discourse}

Halliday's model of discourse analysis, based on what he terms systemic functional grammar, is geared to the study of language as communication, seeing meaning in the writer's linguistic choices and systematically relating these choices to a wider sociocultural framework. It borrows Bühler's tripartite division of language functions. In Halliday's model, there is a strong interrelation between the surface-level realizations of the linguistic functions and the sociocultural framework (Munday, 2011, p.137).

The genre (the conventional text type that is associated with a specific communicative function, for example a business letter) is conditioned by the sociocultural environment and itself determines other elements in the systemic framework. The first of these is register, which comprises three variable elements: (1) field: what is being written about, e.g. a delivery of goods; (2) tenor: who is communicating and to whom, e.g. a sales representative to a customer; (3) mode: the form of communication, e.g. written. Each of the variables of register is associated with a strand of meaning. These strands, which together form the discourse semantics of a text, are the three metafunctions: ideational, interpersonal and textual. The metafunctions are constructed or realized by the lexicogrammar, that is, the choices of wording and syntactic structure. The links are broadly as follows. The field of a text is associated with ideational meaning, which is realized through transitivity patterns (verb types, active/passive structures, participants in the process, etc.). The tenor of a text is associated with interpersonal meaning, which is realized through the patterns of modality (modal verbs and adverbs such as hopefully, should, possibly, and any evaluative lexis such as beautiful, dreadful). The mode of a text is associated with textual meaning, which is realized through the thematic and information structures (mainly the order and structuring of elements in a clause) and cohesion (the way the text hangs together lexically, including the use of pronouns, ellipsis, collocation, repetition, etc.). Analysis of the metafunctions has prime place in this model. The close links between the lexicogrammatical patterns and the metafunctions mean that the analysis of patterns of transitivity, modality, thematic structure and cohesion in a text reveals how the metafunctions are working and how the text 'means' (Eggins 2004: 84). For instance, passages from novels by Ernest Hemingway have often been subjected to a transitivity analysis: so Fowler (1996: 227-32) analyses an extract from Hemingway's Big Two-Hearted River and finds that the dominant transitivity structure is composed of transitive material processes which emphasize the active character of the protagonist, Nick. However, Halliday's grammar is extremely complex, and that is why, in common with the works described in the following sections, the present study has chosen to select and simplify those elements which are of particular relevance for translation. In the case of the first model, Juliane House's, the central concept is register analysis ((Munday, 2011, pp. 137-140).

\section{DATA COLLECTION AND ANALYSIS}

The theoretical framework of the present research is basically associated with the theoretical premises put forward by Halliday. Sadeq Hedayat's work was chosen as the primary ST to be compared closely with its corresponding translated TT by Iraj Bashiri. The ST was wholly read and 
selected as the corpus of the study. Through a sentence-bysentence contrasting, each ST-TT pair of the corpus of the research was detected to be analyzed and categorized. The translated English version of the above work by Iraj Bashiri was available to the researcher. This study is a descriptive research.

The following steps were taken in order to carry out this study. The first step was to read the original Persian text. The next step was to read the English version translated by Bashiri to find the suggested equivalent sentences. Halliday's (1960) SFG was used as the framework of the study. Both texts were selected as required data from the original text and the translated versions which to be analyzed based on basic requirement of discourse style. All data were, then, grouped with their English equivalents. Then, each group was reviewed and the data were analyzed by comparing and contrasting the original sentences and their suggested equivalent counterparts. Next, the features of each element were compared and the results were presented in the Table below.

Table 1. Discourse Analysis under Hallidayan Model

\begin{tabular}{|c|c|c|}
\hline Field & $\begin{array}{c}\text { ST } \\
\text { The subject matter of } \\
\text { the text is about } \\
\text { liberation as human's } \\
\text { natural right. }\end{array}$ & $\begin{array}{c}\text { The subject matter of the } \\
\text { text is about liberation as } \\
\text { human's natural right. }\end{array}$ \\
\hline Tenor & $\begin{array}{c}\text { The fiction addresses } \\
\text { all Iranian people } \\
\text { oppressed under the } \\
\text { difficulties of Reza } \\
\text { Shah's time }\end{array}$ & $\begin{array}{c}\text { The fiction addresses all } \\
\text { non-Persian people } \\
\text { throughout the world to } \\
\text { clarify the intentions of } \\
\text { the ST author and know } \\
\text { the world of Hedayat } \\
\text { through his literary } \\
\text { masterpiece. }\end{array}$ \\
\hline Mode & Written fiction & $\begin{array}{c}\text { Written translation of a } \\
\text { fiction }\end{array}$ \\
\hline
\end{tabular}

\section{CONCLUSION}

To respond the question, the researcher resorted to Halliday's notion of discourse style, based on what he terms Systemic Functional Grammar which is geared to the study of language as communication, seeing meaning in the writer's linguistic choices and systematically relating these choices to a wider sociocultural framework (Munday, 2011, p. 90). In Halliday's model, there is a strong interrelation between the surface-level realizations of the linguistic functions and the sociocultural framework (Munday, 2011, p. 90). Meanwhile, based on the analysis of discourse style under Hallidayan notion, the element of tenor in both our ST and TT is formal, however, ST addresses Persian people living Reza Shah's age but TT has been translated in English to non-Persian people. The field is identical in both texts; because the ST is a literary simple prose text, a fiction, and its translation has maintained the same field as in ST. Mode of ST is a written literary novella and the same is true about TT. Among the limitations of the paper, first of all, access to previous researches was difficult, especially in Iran. Also, some sources were highly expensive or unavailable. Since some of the sources lack the conditions of being known as valid such as having no page number, author's name, or publication date provided the researcher with a lot of problems accessing to the valid references. The last but not the least relates to time; some part of investigation was beyond the scope of the present thesis such as analyzing inter-textual mismatches; therefore, it made the researcher put investigation of those parts for future. In spite of all mentioned limitations, considering the implications of the study, using this model of analysis, students of translation studies can learn how to analyze ST and TT in order to analyze the inter-textual coherence of a fiction and its translated text from Persian into English or any other pairs of languages.

\section{REFERENCES}

[1] Baker, M. \& Saldanha, G. (2013). Rutledge Encyclopedia of Translation Studies. USA and Canada: Routledge.

[2] Bashiri, I. (2013). The Blind Owl ( $3^{\text {rd }}$ ed.). Mineapolise: Minneapolis publications

[3] Feng, Q., \& Wang, R., (2009). Intratextual Coherence in Translating The Tso Chuan. Intercultural Communication Studies XVIII: 2 2009. Dalian University of Technology.

[4] Gambier, Y. \& Doorslaer L. V. (Eds.). (2010). Handbook of Translation Studies. Amsterdam/Philadelphia: John Benjamins Publishing Company.

[5] Hanninen, R. (2006). Translating Magazine Articles: Two Analyses. University of Tampere: School of Modern Languages and Translation Studoes.

[6] Hatim, B. (2013). Teaching and Researching Translation. Great Britain: Pearson Publications

[7] Hedayat, S., (1972). Boof-e-Koor. Tehran: Sepehr publications.

[8] Jahangiri, A. (2012). A study on the circularity of The Blind Owl written by Sadegh Hedayat. Elixir International Journal, 47, 9138-9142 
[9] Jensen, M. N. (2009). Professional Translators' Establishment of Skopos : A 'Brief' Study. retrieved from pure.au.dk/portal/files/7795/Professional_Translators_Establi shment_of_Skopos

[10] Kalliomaki, H. (2007). Translating Fictitious Science: A Case Study on the Translation Process of Two Short Stories by Issac Asmiov. A Pro Gradu Thesis in English: University of Jyvaskyla. $\quad$ Retrieved from https://jyx.jyu.fi/dspace/handle/123456789/7420

[11] Katouzian, H. (2008). Sadeq Hedayat: His Work and His Wondrous World. London and New York: Rutledge

[12] Mei, Z. (2010). On the Translation Strategies of English Film Title from the Perspective of Skopos Theory. Journal of Language Teaching and Research, 1 (1), 66-68. Doi: 10.4304/j1tr.1.1.66-68.

[13] Munday, J. (2011). Introducing Translation Studies. London: Rutledge publications.

[14] Nord, C. (2005). Text Analysis in Translation: Theory, and Didactic Application of a Model for Translation-oriented Text Analysis. Amsterdam-New York, NY, Netherlands: Rodopi. Retrieved from https://is.muni.cz/th/217560/ff_m/DP_Pobocikova.pdf.

[15] Nord, C. (1997). Translating as a Purposeful Activity. Manchester, UK and Kinderhook (NY), USA: ST Jerome publications.

[16] Somers. H. (2003). Computers and Translation. Amsterdam/Philadelphia: John Benjamins Publishing Company.

[17] Wang, J. (2010). "A Critical Discourse Analysis of Barack Obama's Speeches". Journal of Language Teaching and Research, Vol. 1, No. 3, pp. 254-261, May 2010 (C) 2010 ACADEMY PUBLISHER Manufactured in Finland. doi:10.4304/jltr.1.3.254-261.

[18] Mehrabi and Zaker (2014). "A Stylistic Analysis of Some of Golestan Stories Using Halliday's Systemic Functional Linguistics Framework". Language Related Research.Vol.7, No.1 (Tome 29), March, April \& May 2016.

[19] Almurashi, W.A. (2016). “An Introduction to Halliday's Systemic Functional Linguistics”. Journal for the Study of English Linguistics. Vol. 4, No. 1. Taibah University Kingdom of Saudi Arabia. 